\title{
Seasonal Assessment of Heavy Metal Pollution in Street Dust of Nicosia City in North Cyprus
}

\author{
By Rana Kidak ${ }^{1}$
}

\begin{abstract}
Heavy metals concentration is increasingly becoming health concern in the world, particularly on street dust of urban cities with high density traffic. Road dust samples were analyzed for determination of concentrations of the environmentally sensitive elements $\mathrm{As}, \mathrm{Co}, \mathrm{Cr}, \mathrm{Cu}, \mathrm{Ni}, \mathrm{Pb}$, and $\mathrm{Zn}$ in fraction of dust smaller than $100 \mu \mathrm{m}$. The dust particles were collected during winter and summer seasons from highways, residential and industrial areas representing different activities across the Nicosia city. The dust samples were measured for their contamination levels and particles size distribution. The assessment of pollution was based on single pollution indices, integrated pollution indices and Pearson moment correlation in order to determine their possible source, spatial distribution and seasonal variations. Single Indices include Contamination Factor (Cf), Index of Geo-accumulation (Igeo) and the integrated indices include degree of contamination (Dc) and Pollution Load Index (PLI). The general pattern of occurrence of heavy metals follows the order of $\mathrm{Cr}>\mathrm{Zn}>\mathrm{Cu}>\mathrm{Ni}>\mathrm{Pb}>\mathrm{Co}>$ As. The highest levels of $\mathrm{Cr}, \mathrm{Zn}$ and $\mathrm{Cu}$ were found in the high traffic density area, and strong positive correlations were found between these metals, implying that automobile exhausts are the dominant source of these metals.
\end{abstract}

Keywords: Heavy metals, pollution indices, particles size distribution, seasonal variation.

\section{Introduction}

Air pollution nowadays is a significant issue for contemporary urban centers. Improving contamination stages due to fast urbanization and development in exhaust relevant to vehicle transport are now a cause of significant issue. Pollution of the habitat by pollutants is a global issue because these materials are unbreakable and some of these components at high stages can mean toxicological threats (Domingo J.L., 1994).

Road surfaces receive different quantity of pollutants by the process of environmental buildup, through wet and dry deposition, sedimentation, impaction and interception ( $\mathrm{Li}$ X. and Poon C. S., 2001). Particularly in cities, the top soils and street dusts are often signs of heavy metal contamination from environmental buildup. Traffic and industries, exploration activities, smelters and construction are some of the main anthropogenic sources of heavy metal pollution. The traffic source contains automobiles; e.g. tire wear, braking mechanism designs, energy burning, etc. (Pagotto, et al., 2001). Road dust is one of the major source contributors for metal contamination in urban environment. Longterm exposure to the polluted road dust would cause severe damage through of inhalation, ingestion, and dermal contact ( $\mathrm{Lu} \mathrm{X}$, et al. 2010). Heavy metals are conservative pollutants because they tend to bio accumulate, over a period of time; the concentrations of heavy metal within a biological organism can be higher than that of the environment.

${ }^{1}$ Faculty of Engineering, Department of Environmental Engineering, Cyprus International University, Mersin 10, Turkey 
Little interest has been focused on the related field along major roadways in Nicosia city. Hence, there is a need to identify the levels of toxic contaminations in the urban roads because of their association with human health effect. It has been revealed that the average area of asphalt is 3,296,146 $\mathrm{m}^{2}$ considering that the average width is $8.22 \mathrm{~m}$ (27 feet) in Nicosia city (Ziya B., 2013). The objective of this study is to determine and assess contamination levels of some toxic heavy metals such as; $\mathrm{As}, \mathrm{Co}, \mathrm{Cr}, \mathrm{Cu}, \mathrm{Ni}, \mathrm{Pb}$ and $\mathrm{Zn}$ in road dust along the major road sections, to provide the risk factor for each road dust category and to evaluate the status of heavy metal pollution in road dust due to different activities along the roads in Nicosia city.

\subsection{Dispersion of Road Dust Particles}

Particles deposited on vicinity of the road, are often referred to as road dust, these particles may be restrained, or resuspended into atmosphere. The factors that are affecting road dust emissions depend on various environmental and meteorological conditions. The ability of the dust to be resuspended, due to traffic activity, is directly proportional to particle size (Nicholson et al., 1990).

Large particles usual have less ability to resuspend due to the effect of gravitational force. Fine particles with a smaller diameter may remain suspended in air indefinitely, while particles larger than about $200 \mu \mathrm{m}$ settle easily and may not travel far from their sources of release (Sioutas et al., 2005). The exhaust gas from vehicle into the atmosphere generally involves cooling and dilution of particle matter, which may alter their properties including particle number, sizes, surface area and chemical composition.

Northern Cyprus is the second highest after the United States (rated as 842 vehicles per thousand people) in terms of the number of vehicles per capita in the world with 823 vehicles per thousand people, 238,839 de-facto number of the registered vehicles. Luxembourg is a close follower of Northern Cyprus with 697 vehicles per thousand people (Ucar, H., 2011).

\subsection{Transportation in North Cyprus}

There are three modes of transportation in Nicosia of North Cyprus these are;

- Road transport system this involve usually the used of min bus popular known as "Dolmus".

- Air transport system which is done through the Ercan Airport via Turkish international airports.

- Sea transport is usually carried out through the use of ferry boats and sea-buses, travelling from Turkey to Kyrenia and Famagusta port of North Cyprus.

Among all the means of transport listed, the inland transport is the most common which is mostly covered by vehicle passenger cars. The total green in the North Nicosia is estimated to be 1,123,695 square meter which include water bodies as one third of the area and the remaining two third as a plain soil (Ziya B. 2013). The asphalt is approximately 3,296,146 square meters considering the average width of 8.22 meters carriage way according to Ziya B., 2013. The air pollutants linked with vehicle exhaust are particulate matter and volatile organic matter. The amount of particulate matter in Nicosia is $64 \mu \mathrm{g} / \mathrm{m} 3$, which is above annual limit value set by the EU of $40 \mu \mathrm{g} / \mathrm{m} 3$ (Baki 
et al., 2010). However, volatile organic in benzene is below the limit value of $5 \mu \mathrm{g} / \mathrm{m} 3$.

\section{Experimental Work}

\subsection{Field Sampling and Sample Preparation}

Nine roads across the Nicosia city were selected in order to compare the contamination levels of heavy metals and to study their distributions, using sediment quality guideline. The sites for the road dust measurements represent different types of activities affecting the city (i.e. residential, heavy traffic road and industrial road) as shown in Figure 1.

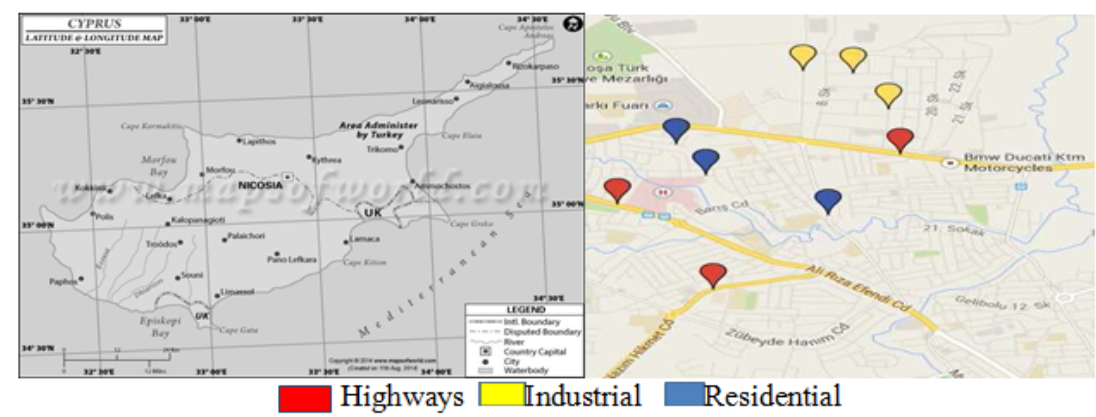

Figure 1: Map of North Cyprus and Sampling points in the Nicosia City

Sampling sites are characterized by different traffic density, number stop point and speed zone, location of the road. Chosen sampling sites include:

(a) Three sites within the residential road area (relatively low traffic),

(b)Three sites in the highways (the busiest with high volume traffic),

(c) Three sites representing the main industrial road (medium traffic volume).

The samples were taken in two different seasons of the year (winter and summer). The samples in winter period were mostly wet samples because of the rain, whereas the summer samples were absolutely dry. At each sampling point, approximately $150 \mathrm{~g}$ of dust particles were collected on pavement surfaces of the road, with a clean plastic dustpan and a brush. The dust was then transferred to self-sealing polyethylene bags, ready for the laboratory analysis. The samples were left to dry at room temperature for ten days (winter sample). The fraction of the dust that passed through sieve sizes between $62.5 \mu \mathrm{m}-100 \mu \mathrm{m}$ is used for the analysis.

The following Analytical and statistical methods were applied to make the required analyses.

- XRF (X-Ray Fluorescence) Analysis

- PSD (The particles size distribution) Analysis

- Single Indices: Contamination Factor $\left(\mathrm{C}_{\mathrm{f}}\right)$, Index of Geo-Accumulation $\left(\mathrm{I}_{\text {geo }}\right)$

- Integrated indices: Degree of contamination $\left(D_{c}\right)$, Pollution Load Index (PLI 


\section{Results and Discussion}

\subsection{Laboratory Results}

\subsubsection{XRF (X-Ray Fluorescence) Analysis}

The concentrations of all the seven heavy metals were analyzed (As, Co, Cr, Cu, $\mathrm{Ni}, \mathrm{Pb}$, and $\mathrm{Zn}$ ) using $\mathrm{X}$-ray fluorescence method. The concentrations are presented below, where nine roads are considered for the sampling, which include Highways, Residential Roads and Industrial Roads. Three dust samples per road are collected during two different seasons of the year (i.e. winter and summer). The seasonal and average concentrations are presented in Table 1 and the results for the average are presented in Figure 2.

Table 1: Winter and Summer Concentration of Heavy Metals $(\mathrm{mg} / \mathrm{kg})$

\begin{tabular}{|c|c|c|c|c|c|c|c|c|c|c|c|}
\hline elements & H1 & H2 & H3 & R1 & R2 & R3 & I1 & I2 & I3 & WHO & EPA \\
\hline $\mathrm{Cu}(\mathrm{W})$ & 50.7 & 41.1 & 56.7 & 56.7 & 40.7 & 44.7 & 59.0 & 62.6 & 58.5 & \multirow{3}{*}{25.0} & \multirow{3}{*}{16.0} \\
\hline $\mathrm{Cu}(\mathrm{S})$ & 224.9 & 30.6 & 61.9 & 46.3 & 54.1 & 36.9 & 41.5 & 57.1 & 46.7 & & \\
\hline $\mathrm{Cu}$ (avg) & 137.8 & 35.9 & 59.3 & 51.5 & 47.4 & 40.8 & 50.3 & 59.9 & 52.6 & & \\
\hline $\mathrm{Ni}(\mathrm{W})$ & 81.3 & 57.0 & 46.0 & 51.5 & 80.1 & 72.7 & 57.0 & 45.6 & 42.4 & \multirow{3}{*}{20.0} & \multirow{3}{*}{16.0} \\
\hline $\mathrm{Ni}(\mathrm{S})$ & 52.6 & 37.7 & 41.4 & 39.6 & 40.5 & 86.8 & 62.9 & 66.8 & 64.8 & & \\
\hline Ni (avg) & 67.0 & 47.3 & 43.7 & 45.5 & 60.3 & 79.8 & 59.9 & 56.2 & 53.6 & & \\
\hline $\mathrm{Cr}(\mathrm{W})$ & 420.4 & 296.9 & 269.5 & 279.1 & 297.6 & 288.4 & 345.9 & 321.5 & 330.7 & \multirow{3}{*}{25.0} & \multirow{3}{*}{25.0} \\
\hline $\operatorname{Cr}(\mathrm{S})$ & 289.0 & 303.8 & 209.2 & 256.5 & 232.9 & 626.1 & 388.2 & 409.8 & 398.5 & & \\
\hline Cr (avg) & 354.7 & 300.3 & 239.4 & 267.8 & 265.2 & 457.3 & 367.1 & 365.6 & 364.6 & & \\
\hline $\mathrm{Co}(\mathrm{W})$ & 29.8 & 14.6 & 0.0 & 8.5 & 11.0 & 0.0 & 2.8 & 5.7 & 9.6 & \multirow{3}{*}{ NA } & \multirow{3}{*}{ NA } \\
\hline $\operatorname{Co}(\mathrm{S})$ & 0.0 & 12.8 & 9.5 & 11.1 & 10.3 & 32.3 & 0.0 & 15.3 & 10.3 & & \\
\hline Co (avg) & 14.9 & 13.7 & 4.7 & 9.8 & 10.7 & 16.2 & 1.4 & 10.5 & 9.9 & & \\
\hline $\mathrm{Zn}(\mathrm{W})$ & 587.5 & 85.5 & 120.5 & 110.8 & 76.7 & 80.7 & 109.8 & 125.2 & 185.6 & \multirow{3}{*}{123.0} & \multirow{3}{*}{110.0} \\
\hline $\mathrm{Zn}(\mathrm{S})$ & 65.9 & 51.5 & 53.8 & 52.7 & 53.2 & 41.4 & 82.3 & 91.6 & 83.1 & & \\
\hline Zn (avg) & 326.7 & 68.5 & 87.1 & 81.8 & 65.0 & 61.0 & 96.0 & 108.4 & 134.3 & & \\
\hline As (W) & 6.8 & 5.7 & 0.0 & 0.0 & 0.0 & 6.4 & 4.3 & 1.4 & 2.1 & \multirow{3}{*}{10.0} & \multirow{3}{*}{10.0} \\
\hline As (S) & 4.9 & 0.0 & 0.0 & 0.0 & 0.0 & 15.3 & 0.0 & 8.0 & 0.0 & & \\
\hline As (avg) & 5.90 & 2.80 & 0 & 0 & 0 & 10.90 & 2.10 & 4.70 & 1.10 & & \\
\hline $\mathrm{Pb}(\mathrm{W})$ & 18.1 & 26.5 & 51.2 & 53.4 & 34.3 & 17.6 & 33.5 & 50.9 & 46.8 & \multirow{3}{*}{ NA } & \multirow{3}{*}{40.0} \\
\hline $\mathrm{Pb}(\mathrm{S})$ & 20.0 & 35.9 & 27.8 & 31.9 & 29.9 & 0.0 & 34.3 & 14.4 & 31.6 & & \\
\hline $\mathrm{Pb}$ (avg) & 19.0 & 31.2 & 39.5 & 42.6 & 32.1 & 8.8 & 33.9 & 32.6 & 39.2 & & \\
\hline
\end{tabular}

\section{$\mathrm{W}=$ winter $\mathrm{S}=$ summer}

It was very obvious that $\mathrm{Cu}, \mathrm{Cr}$ and $\mathrm{Zn}$ were the most abundant heavy metals found in all classes of streets in the city (WHO standards). While the concentrations of $\mathrm{Pb}$ and $\mathrm{As}$ are within the limit values, that of Co were not reported by the standard. In this study there are two major contributors of pollution in street dust: these are anthropogenic and lithogenic. The lithogenic effects come from origin of the material while anthropogenic effects come from vehicles exhaust and industrial waste. 


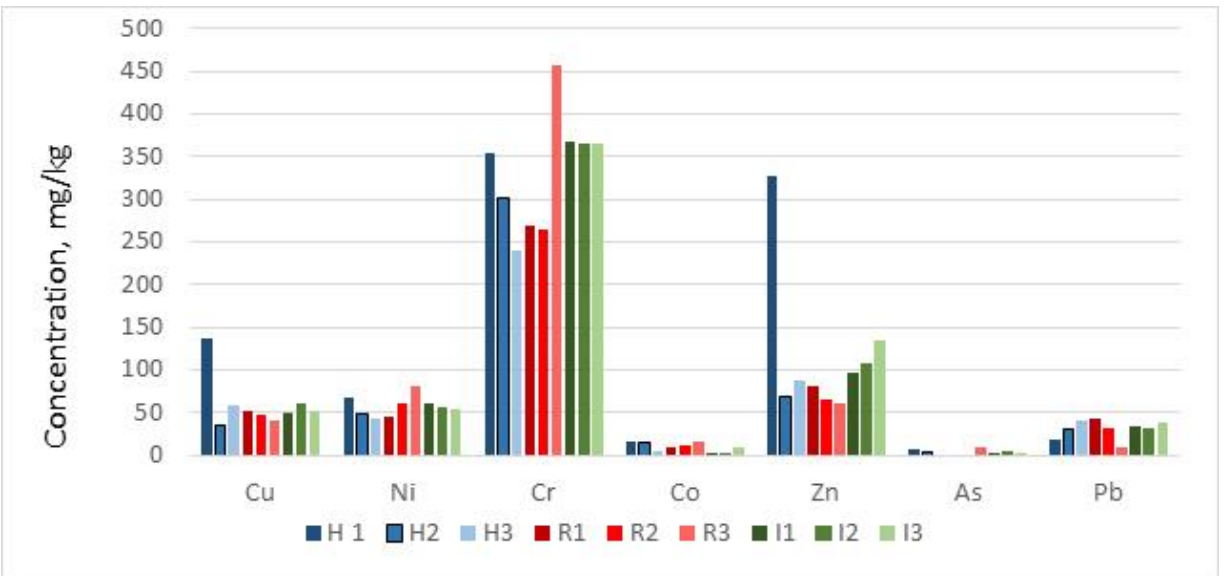

Figure 2. Average Heavy Metals Distribution in Nicosia

Among all the studied areas, highways were found to have the highest average concentrations, followed by industrial and residential roads. This shows that traffic volume is the major contribution to pollution. The metals follow the decreasing order of $\mathrm{Cr}>\mathrm{Zn}>\mathrm{Cu}>\mathrm{Ni}>\mathrm{Pb}>\mathrm{Co}>\mathrm{As}$. $\mathrm{Cu}, \mathrm{Cr}, \mathrm{Co}$ and $\mathrm{As}$ are larger in summer and $\mathrm{Ni}$ and $\mathrm{Zn}$ are larger in winter.

\subsubsection{PSD (Particles size distribution) Analysis}

The particle size of street dust is an important parameter in the analysis of heavy metals concentration. Particle size is usually described by the diameter of the particle. In this work the Mastersizer2000 Laser diffraction device is used for the analysis. The degree of harmful effect of inhaled street dust is often related with dust particle size. The particle size distribution curves of samples show correlative distribution patterns manifested by the overlapping curves. Figure3 is residential, Figure4 is highway and Figure 5 is industrial dust analysis for their particle sizes. The graphs were used to deduce the values of $\mathrm{d} 10, \mathrm{~d} 30$ and $\mathrm{d} 60$. The definition of the di is as follows: $\mathrm{d} 10=$ grain diameter at $10 \%$ passing, $\mathrm{d} 30=$ grain diameter at 30\% passing, $\mathrm{d} 60=$ grain diameter at $60 \%$ passing.
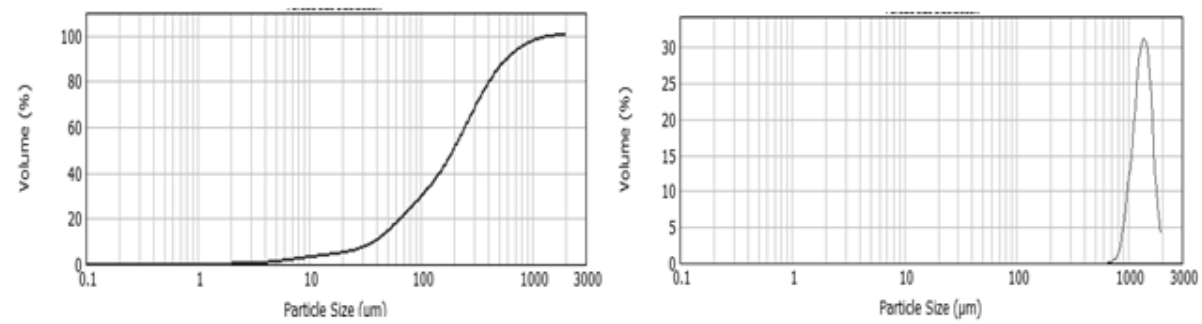

Figure 3: Residential Dust Particle Size in Winter (a) and Summer (b)

The Figure 3 a shows that in summer the particles distribution of the dust sample is immediate between fine and coarse particles class.. On the other hand Figure 3b shows 
that the particles are evenly distributed with a high percentage of coarse particles in sample dust. This indicates the dust is not well graded
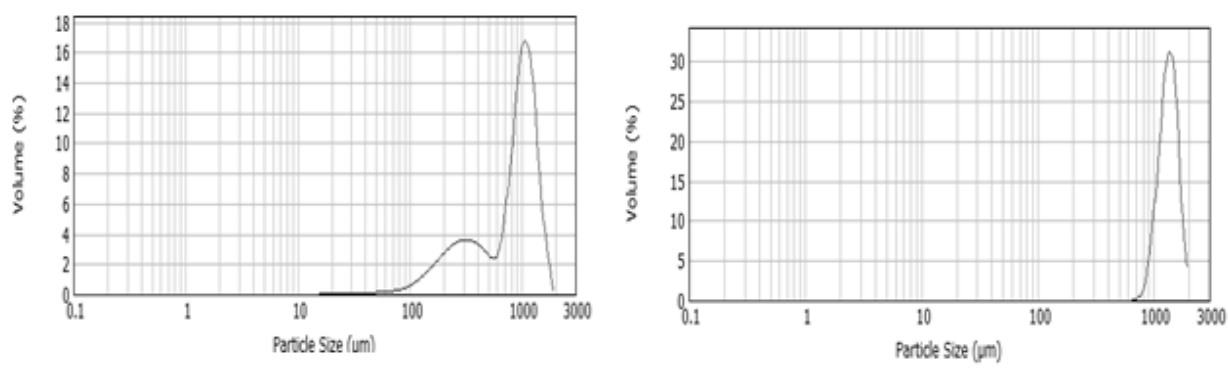

Figure 4: Highways Dust Particle Size in Winter (a) and Summer (b)

Figure 4 for the highways in winter shows that finer particles between 0 to $800 \mu \mathrm{m}$ are more or less absent in this dust sample site. Coarse particles are within a range of $850 \mu \mathrm{m}$ to $2500 \mu \mathrm{m}$ this show that the soil is more of coarse particles In summer, the same pattern is observed with a very slight difference.
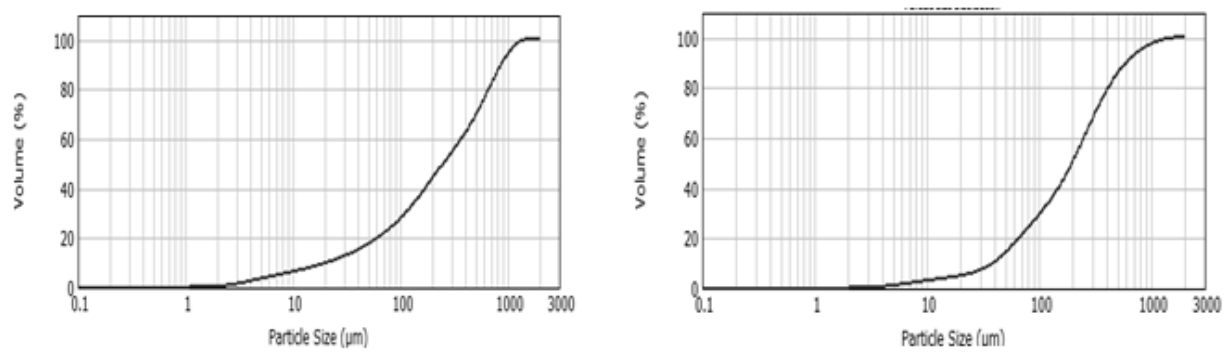

Figure 5: Industrial Dust Particle Size in Winter (a) and Summer (b)

Figure 5 shows that the particles are evenly distributed with a high percentage of coarse particles in samples both in Summer and Winter.

\subsection{Single Indices}

\subsubsection{Average Seasonal Contamination Factors $\left(\mathrm{C}_{\mathrm{f}}\right)$}

A Contamination Factor is an indicator used to describe the toxic nature of substances in a lake or sub basin (Hakanson 1980). It is defined as the ratio of heavy metal concentration obtained to the ratio in sediment or background samples.

$\boldsymbol{C f}=\frac{C i}{B n}$

where

$\mathrm{C}_{\mathrm{i}}=$ mean concentration of substance,

$\mathrm{B}_{\mathrm{n}}=$ background sample response value $(\mathrm{mg} / \mathrm{kg})$,

$\mathrm{C}_{\mathrm{f}}<1$ low contamination factor, $1 \leq \mathrm{C}_{\mathrm{f}}<3$, moderate contamination factor, $3 \leq \mathrm{C}_{\mathrm{f}}<6$ considerable contamination factor, $\mathrm{C}_{\mathrm{f}} \geq 6$, very high contamination factor.

In Table 2 the background sample response values are given for Nicosia, from a previous work. Table 3 below shows the base average values obtained from four different 
sediments in the inland by Duman et al. 2012.Contamination factor $\left(C_{f}\right)$ of the seven studied heavy are present in Table $2, \mathrm{Cu}, \mathrm{Zn}$ and $\mathrm{Pb}$ are moderately polluted, pollution of $\mathrm{Ni}, \mathrm{Co}$ and $\mathrm{As}$ are very low while that of $\mathrm{Cr}$ is considerable high. The degree of contamination in winter reveals that the entire roads chosen in this research work are "moderately polluted" with exception of H1 and R3 which are "considerable polluted".

Table 2: Background samples response value in $\mathrm{mg} / \mathrm{kg}$

\begin{tabular}{|c|c|c|c|c|c|c|}
\hline Element $(\mathrm{ppm})$ & $\mathrm{Cu}$ & $\mathrm{Ni}$ & $\mathrm{Cr}$ & $\mathrm{Co}$ & $\mathrm{As}$ & $\mathrm{Pb}$ \\
\hline pre industrial $(\mathrm{Bn}) 1$ & 45.000 & 68.000 & 90.000 & 19.000 & 13.000 & 20.000 \\
\hline
\end{tabular}

*(1) Duman 2012 (2) Hakanson 1980

Table 3: Average Seasonal Contamination Factors $\left(\mathrm{C}_{\mathrm{f}}\right)$

\begin{tabular}{|c|c|c|c|c|c|c|c|c|c|c|c|c|c|c|}
\hline Roads & $\mathrm{CuW}$ & $\mathrm{CuS}$ & $\mathrm{NiW}$ & $\mathrm{NiS}$ & $\mathrm{CrW}$ & $\mathrm{CrS}$ & CoW & $\mathrm{CoS}$ & $\mathrm{ZnW}$ & $\mathrm{ZnS}$ & AsW & AsS & $\mathrm{PbW}$ & $\mathrm{PbS}$ \\
\hline H1 & 1.1 & \begin{tabular}{|l|}
5.0 \\
\end{tabular} & 1.2 & 0.8 & 4.7 & 3.2 & 1.6 & 0.0 & 6.2 & 0.7 & 0.5 & 0.4 & 0.9 & \begin{tabular}{|l|}
1.0 \\
\end{tabular} \\
\hline $\mathrm{H} 2$ & 0.9 & 0.7 & 0.8 & 0.6 & 3.3 & 3.4 & 0.8 & 0.7 & 0.9 & 0.5 & 0.4 & 0.0 & 1.3 & \begin{tabular}{|l|}
1.8 \\
\end{tabular} \\
\hline H3 & 1.3 & 1.4 & 0.7 & 0.6 & 3.0 & 2.3 & 0.0 & 0.5 & 1.3 & 0.6 & 0.0 & 0.0 & 2.6 & \begin{tabular}{|l|}
1.4 \\
\end{tabular} \\
\hline R1 & 1.3 & 1.0 & 0.8 & 0.6 & 3.1 & 2.8 & 0.4 & 0.6 & 1.2 & 0.6 & 0.0 & 0.0 & 2.7 & \begin{tabular}{|l|}
1.6 \\
\end{tabular} \\
\hline $\mathrm{R} 2$ & 0.9 & 1.2 & 1.2 & 0.6 & 3.3 & 2.6 & 0.6 & 0.5 & 0.8 & 0.6 & 0.0 & 0.0 & 1.7 & \begin{tabular}{|l|}
1.5 \\
\end{tabular} \\
\hline R3 & 1.0 & 0.8 & 1.1 & 1.3 & 3.2 & 7.0 & 0.0 & 1.7 & 0.8 & 0.4 & 0.5 & 1.2 & 0.9 & 0.0 \\
\hline I1 & 1.3 & 0.9 & 0.8 & 0.9 & 3.8 & 4.3 & 0.1 & 0.0 & 1.2 & 0.9 & 0.3 & 0.0 & 1.7 & 1.7 \\
\hline $\mathrm{I} 2$ & 1.4 & 1.3 & 0.7 & 1.0 & 3.6 & 4.6 & 0.3 & 0.8 & 1.3 & 1.0 & 0.1 & 0.6 & 2.5 & \begin{tabular}{|l|}
0.7 \\
\end{tabular} \\
\hline $\mathrm{I} 3$ & 1.3 & 1.0 & 0.6 & 1.0 & 3.7 & \begin{tabular}{|l|}
4.4 \\
\end{tabular} & 0.5 & \begin{tabular}{|l|}
0.5 \\
\end{tabular} & 2.0 & 0.9 & 0.2 & 0.0 & 2.3 & 1.6 \\
\hline Avg. & \multicolumn{2}{|c|}{1.3} & \multicolumn{2}{|c|}{0.8} & \multicolumn{2}{|c|}{$\frac{1}{3.7}$} & \multicolumn{2}{|c|}{0.5} & \multicolumn{2}{|c|}{1.2} & \multicolumn{2}{|c|}{0.2} & \multicolumn{2}{|c|}{1.6} \\
\hline
\end{tabular}

\subsubsection{Geo-Accumulation Index (Igeo)}

Index of geo accumulation was originally defined in 1969 in order to determine and define heavy metal contamination in sediments.

Igeo $=\log _{2}\left\{\frac{C i}{1.5 B n}\right\}$

where

$\mathrm{Ci}=$ mean concentration of substance, $\mathrm{Bn}=$ sample background value

$\mathrm{I}_{\text {geo }} \leq 0$ un-polluted, $0 \leq \mathrm{I}_{\text {geo }}<1$, un-polluted to moderate polluted, $1 \leq \mathrm{I}_{\text {geo }}<3$ moderate to strongly polluted, $\mathrm{I}_{\text {geo }} \geq 3$, extremely polluted

For the street dust, the concentration of $\mathrm{Cu}, \mathrm{Ni}, \mathrm{Co}, \mathrm{Zn}, \mathrm{As}, \mathrm{Pb}$ are considered to be "unpolluted" on this indice for the two seasons and the concentration of $\mathrm{Cr}$ is ranging from "upolluted to moderate polluted". Based on this indice, the concentration of the heavy metals in the remaining samples unchange throughout the seasons.

Table 4: Index of Geo-Accumulation of Samples

\begin{tabular}{|c|c|c|c|c|c|c|c|c|c|c|c|c|c|c|}
\hline Road & $\mathrm{CuW}$ & $\mathrm{CuS}$ & $\mathrm{NiW}$ & $\mathrm{NiS}$ & $\mathrm{CrW}$ & $\mathrm{CrS}$ & $\mathrm{CoW}$ & $\mathrm{CoS}$ & $\mathrm{ZnW}$ & $\mathrm{ZnS}$ & $\mathrm{AsW}$ & $\mathrm{AsS}$ & $\mathrm{pbW}$ & $\mathrm{pbS}$ \\
\hline $\mathrm{H} 1$ & -0.4 & 1.7 & -0.3 & -1.0 & 1.6 & 1.1 & 0.1 & -4.8 & 2.0 & -1.1 & -1.5 & -2.0 & -0.7 & -0.6 \\
\hline $\mathrm{H} 2$ & -0.7 & -1.1 & -0.8 & -1.4 & 1.1 & 1.2 & -1.0 & -1.2 & -0.7 & -1.5 & -1.8 & -4.3 & -0.2 & 0.3 \\
\hline H3 & -0.3 & -0.1 & -1.1 & -1.3 & 1.0 & 0.6 & -4.8 & -1.6 & -0.2 & -1.4 & -4.3 & -4.3 & 0.8 & -0.1 \\
\hline R1 & -0.3 & -0.5 & -1.0 & -1.4 & 1.0 & 0.9 & -1.7 & -1.4 & -0.4 & -1.4 & -4.3 & -4.3 & 0.8 & 0.1 \\
\hline
\end{tabular}




\begin{tabular}{|c|c|c|c|c|c|c|c|c|c|c|c|c|c|c|}
\hline R2 & -0.7 & -0.3 & -0.3 & -1.3 & 1.1 & 0.8 & -1.4 & -1.5 & -0.9 & -1.4 & -4.3 & -4.3 & 0.2 & 0.0 \\
\hline R3 & -0.6 & -0.9 & -0.5 & -0.2 & 1.1 & 2.2 & -4.8 & 0.2 & -0.8 & -1.8 & -1.6 & -0.3 & -0.8 & -4.9 \\
\hline I1 & -0.2 & -0.7 & -0.8 & -0.7 & 1.4 & 1.5 & -3.3 & -4.8 & -0.4 & -0.8 & -2.2 & -4.3 & 0.2 & 0.2 \\
\hline I2 & -0.1 & -0.2 & -1.2 & -0.6 & 1.3 & 1.6 & -2.3 & -0.9 & -0.2 & -0.6 & -3.8 & -1.3 & 0.8 & -1.1 \\
\hline I3 & -0.2 & -0.5 & -1.3 & -0.7 & 1.3 & 1.6 & -1.6 & -1.5 & 0.4 & -0.8 & -3.2 & -4.3 & 0.6 & 0.1 \\
\hline Avg. Igeo & \multicolumn{2}{|c|}{-0.3} & \multicolumn{2}{|c|}{-0.9} & \multicolumn{2}{|c|}{1.2} & \multicolumn{2}{|c|}{-1.6} & \multicolumn{2}{|c|}{-0.7} & -2.6 & \multicolumn{2}{|c|}{-0.2} \\
\hline
\end{tabular}

$\square$ Low pollution $\square$ Moderate pollution $\square$ High pollution $\square$ Considerable pollution $\square$ Extreme pollution

\subsection{Integrated Indices}

\subsubsection{Degree of Contamination $\left(\mathrm{D}_{\mathrm{c}}\right)$}

The Degree of Contamination can be defined as the sum of all contamination factors in the sample for give site.

$D c=\sum_{1}^{n} \boldsymbol{C f}$

where

$\mathrm{C}_{\mathrm{f}}=$ single contamination factor,

$\mathrm{n}=$ The count of the studied heavy metals

$\mathrm{D}_{\mathrm{c}}<\mathrm{n}$ : Low pollution, $\mathrm{n} \leq \mathrm{D}_{\mathrm{c}}<2 \mathrm{n}$ : Moderate pollution, $\mathrm{D}_{\mathrm{c}}>4 \mathrm{n}$ : Considerable pollution The values are presented in Table 5 below.

\subsubsection{Pollution Load Index (PLI)}

Pollution load index (PLI) for the sediments at each site was evaluated by the method of Tomilson et al. (1980), this method provides basic understanding of a component in the environment. Pollution load index of a single site is defined as the nth root of n number of multiplied Contamination factor $\left(\mathrm{C}_{\mathrm{f}}\right)$ values.

$P L I=\left\{C_{f 1} x C_{f 2} x C_{f 3} x \ldots \ldots \ldots \ldots C_{f n}\right\}^{1 / n}$

PLI $=0$ Not Polluted

PLI=1 Moderate pollution

PLI $>1$ Considerable pollution

In summer H3 and R2 had "low degree of contamination" while the rest have "moderate degree of contamination". The pollution load indices in winter shows that "H1 and I3 are polluted" and in summer only road "I2 is polluted".

Table 5: Degree of Contamination $\left(\mathrm{D}_{\mathrm{c}}\right)$ and Pollution Load Indices (PLI)

\begin{tabular}{|c|c|c|c|c|c|c|c|c|}
\hline Road & Dc & Winter & Dc & summer & PLI & Winter & PLI & Summer \\
\hline H1 & 16.18 & Considerable & 11.05 & moderate & 1.62 & polluted & 0.00 & Not polluted \\
\hline H2 & 8.48 & Moderate & 7.62 & moderate & 1.00 & polluted & 0.00 & Not polluted \\
\hline H3 & 8.76 & Moderate & 6.77 & low & 0.00 & Not polluted & 0.00 & Not polluted \\
\hline R1 & 940 & Moderate & 7.19 & moderate & 0.00 & Not polluted & 0.00 & Not polluted \\
\hline R2 & 8.50 & Moderate & 6.98 & low & 0.00 & Not polluted & 0.00 & Not polluted \\
\hline R3 & 7.49 & Moderate & 12.37 & moderate & 0.00 & Not polluted & 0.00 & Not polluted \\
\hline I1 & 9.30 & Moderate & 8.75 & moderate & 0.88 & Not polluted & 0.00 & Not polluted \\
\hline I2 & 9.91 & Moderate & 9.90 & moderate & 0.87 & Not polluted & 1.94 & Not polluted \\
\hline I3 & 10.55 & Moderate & 9.42 & moderate & 1.01 & polluted & 0.00 & Not polluted \\
\hline
\end{tabular}




\subsection{Pearson Moment Correlation}

Pearson's moment correlation ( $r$ ) is a statistical tool used for the examining the relationship between two variables that are measured on the same interval or ratio scale. In metal analysis, positive correlation indicates strong relationships between contaminants, while negative correlation indicates weak relationship (different source) between the contaminants. The correlations of the 7 heavy metals were analyzed by using the Pearson Product Moment correlation coefficient Table 6. The analysis shows that correlations between heavy metals is in decreasing order of the coefficient: positive correlation $(\mathrm{Cu} / \mathrm{Zn})>(\mathrm{As} / \mathrm{Cr})>(\mathrm{As} / \mathrm{Ni})>(\mathrm{Ni} / \mathrm{Cr})>(\mathrm{As} / \mathrm{Co})$, Negative correlation: $(\mathrm{Pb} / \mathrm{Co})>(\mathrm{Pb} / \mathrm{Cr})>(\mathrm{Pb} / \mathrm{Ni})>(\mathrm{Pb} / \mathrm{As})$.

Table 6: Pearson Product Moment correlation coefficient

\begin{tabular}{|c|c|c|c|c|c|c|c|c|}
\hline Elements & & $\mathrm{Cu}$ & $\mathrm{Ni}$ & $\mathrm{Cr}$ & $\mathrm{Co}$ & $\mathrm{Zn}$ & $\mathrm{As}$ & $\mathrm{Pb}$ \\
\hline $\mathrm{Cu}$ & & $\mathbf{1}$ & & & & & & \\
\hline $\mathrm{Ni}$ & & 0,228 & $\mathbf{1}$ & & & & & \\
\hline $\mathrm{Cr}$ & & 0,059 & $\mathbf{0 , 8 0 9}$ & $\mathbf{1}$ & & & & \\
\hline $\mathrm{Co}$ & & 0,225 & 0,469 & 0,362 & $\mathbf{1}$ & & & \\
\hline $\mathrm{Zn}$ & & $\mathbf{0 , 9 7 2}$ & 0,237 & 0,160 & 0,261 & $\mathbf{1}$ & & \\
\hline $\mathrm{As}$ & & 0,186 & $\mathbf{0 , 8 3 4}$ & $\mathbf{0 , 8 5 1}$ & 0,621 & 0,204 & $\mathbf{1}$ & \\
\hline $\mathrm{Pb}$ & & $-0,275$ & $\mathbf{- 0 , 9 0 3}$ & $\mathbf{- 0 , 7 1 9}$ & $-0,658$ & $-0,271$ & $\mathbf{- 0 , 9 2 9}$ & $\mathbf{1}$ \\
\hline
\end{tabular}

Values in bold are different from 0 with a significance level alpha $=0,05$

The correlation coefficient between copper and zinc $(r=0.972)$ which is quiet in agreement with research of this type, indicating the highest correlation. Other major correlation include chromium and arsenic $(\mathrm{r}=0.851)$, arsenic and nickel $(\mathrm{r}=0.834)$, chromium and nickel ( $\mathrm{r}=0.809)$, arsenic and cobalt $(\mathrm{r}=0.621) . \mathrm{Cu}, \mathrm{Zn}, \mathrm{Ni}, \mathrm{As}$, and $\mathrm{Cr}$ are usually generated from anthropogenic sources (Kim CH et al. 2010). Lead (Pb) shows negative correlation with $\mathrm{Ni}, \mathrm{Co}, \mathrm{Cr}$, and As; this indicates that the presence of lead in streets does not necessary come from vehicle exhaust as a result of regulation imposed in the use of unleaded fuel. On the other hand $\mathrm{Cr}$ present in soil dust mostly comes from diesel (Kittelson D.B., 2001). $\mathrm{Cu}$ and $\mathrm{Zn}$ are usually from tire and engine part corrosion (Adachi K and Tainosho Y, 2010).

During sampling in winter, Nicosia had witnessed a diurnal temperature variation of 10 degree Celsius and a high relative humidity of $78 \%$ and a wind speed of $2 \mathrm{~m} / \mathrm{s}$. This condition favored some accumulation of pollutants in the streets such as zinc and copper which can easily react with soil in the presence of moisture to form zinc oxide and copper oxide. In summer the average temperature is relatively high ( 33 degree Celsius) and a very low relative humidity of $42 \%$ with a wind speed of $3 \mathrm{~m} / \mathrm{s}$. This condition is less favorable when compared to winter season.

\section{Conclusion}

The concentrations and particle size distributions of heavy metals were measured using XRF and the Mastersizer2000, respectively. The fractional size of street dust between $62.5 \mu \mathrm{m}$ to $1 \mathrm{~mm}$ is used for the XFR measurements. Seasonal variation was 
observed in three zones of environment (Highways, Residential and Industrial area). Both single and integrated pollution indices were studied in order to determine the possible contamination of heavy metals by vehicles exhaust. Single Indices include Contamination Factor $\left(C_{f}\right)$, Index of Geo-accumulation $\left(I_{g e o}\right)$ and the integrate indices include degree of contamination $\left(D_{c}\right)$ and Pollution Load Index (PLI). Seasonal variations in soil texture were also observed: residential and industrial street soil changes from "Fine Sand in winter to Medium Sand in summer", whereas for the busy traffic no significant change was observed throughout the seasons.

The contamination factor for the studied samples indicates $\mathrm{Ni}$, As and Co had "Iow contamination factor", $\mathrm{Cu}, \mathrm{Pb}$ and $\mathrm{Zn}$ had "moderate contamination factor", and $\mathrm{Cr}$ had "Considerable contamination factor". The factor follows the decreasing of $\mathrm{Cr}>\mathrm{Pb}>\mathrm{Cu}>\mathrm{Zn}>\mathrm{Ni}>\mathrm{Co}>$ As. Highways in winter and Residential roads in summer had "high pollution".

Index of Geo-accumulation reveals that seven elements are categorized as "unpolluted sample" with exception of $\mathrm{Cr}$ which is moderately polluted sample. The work did not reveal statistical differences on the levels of $\mathrm{Cr}, \mathrm{Zn}$ and $\mathrm{Cu}$ between seasons. Winter average values for $\mathrm{Pb}, \mathrm{Zn}$ and $\mathrm{Ni}$ exceeded corresponding summer values. In arid regions opposite patterns were observed. In general contamination of heavy metals, in all sites studied, were statistically not different from each other, except at high traffic site. The street dust should be continually monitored over time. The aim of monitoring would help in putting adequate measures in vehicle emission control. Alternative means of transportation should be provided by the government so that number of vehicle per capita can be reduced drastically e.g. buildup a rail ways system across the city.

\section{References}

Adachi, K. and Tainosho, Y. (2010). Characterization of heavy metal particles embedded in tire dust, Environment International, 44(7), 299-304. DOI:10.1016/j.envint.2004.04.004

Baki, T. and Diran, Ö. A. (2010). Turkish Republic of Northern Cyprus, Air Quality Report, Nicosia: TRNC, Department of Environmental Protection, Air Emission Branch.

Domingo, J. L. (1994). Metal-induced developmental toxicity in mammals: A review. Journal of Toxicological Environmental Health, 42, 123-141. DOI:10.1080/15287399409531868

Duman M, Kucuksezgin F, Atalar M, Akcali B (2012). Geochemistry of the Northern Cyprus (NE Mediterranean) shelf sediments: implications for anthropogenic and lithogenic impact. Marine Pollution Bulletin, 64, 2245-2250. DOI: 10.1016/j.marpolbul.2012.06.025

Hakanson, L. (1980). An Ecological Risk Index for Aquatic Pollution Control: A Sedimentological Approach, Water Research, 14, 975-1001, doi:10.1016/0043-1354(80)90143-8.

Kim, C.H., Yoo, D. C., Kwon, Y. M., Han, W. S., Kim, G. S., Park, M. J., Kim, Y. S. and Choi, D. (2010). A Study on Characteristics of Atmospheric Heavy Metals in Subway Station, Toxicology Research, 26(2), 157-162. https://doi.org/10.5487/TR.2010.26.2.157

Kittelson, D., Johnson, J., Watts, W., Wei, Q. (2000). Diesel Aerosol Sampling in the Atmosphere, SAE Technical Paper 2000-01-2212. doi:10.4271/2000-01-2212

Li X., Poon C.S. and Liu P.S. (2001). Heavy metal contamination of urban soils and street dusts in Hong Kong, Applied Geochemistry, 16, 1361-1368. http://dx.doi.org/10.1016/S0883-2927(01)00045-2

Lu X, Wang L. (2010). Multivariate statistical analysis of heavy metals in street dust of Baoji, NW China, Journal of Hazardous Materials, 173, 744-749. DOI: 10.1016/j.jhazmat.2009.09.001

Nicholson, K.W., and Branson, J.R., (1990). Factors affecting re suspension by road traffic, Science of the Total Environment, 93, 349-358. 
Pagotto C., Rémy N., Legret M, Le Cloirec P. (2001). Heavy metal pollution of Road dust and road side soil near a major rural highway, Environmental Technology, 22, 307-319. doi: $10.1080 / 09593332208618280$

Sioutas, C., Delfino, R. J. and S. Manisha (2005). Exposure assessment for atmospheric ultrafine particles (UFPs) and implications in epidemiologic research. Environmental Health Perspectives, 113, 947955. doi: 10.1289/ehp.7939

Tomlinson D. L., Wilson J. G., Harris C. R. and Jeffrey D. W., (1980). Problem in assessment of heavy metals in estuaries and the formation of pollution index, Helgoländer Meeresuntersuchungen, 33(1) 566-575. doi:10.1007/BF02414780

Ucar, H. (2011). Dünya sıralamasında ikinciyiz) (in Turkish), (2011, February 14th). Retrieved from http://www.kibrisgazetesi.com/index.php/cat/2/news/111741/PageName/Ic_Haberler

Ziya, B. (2013). CypRail: Revitalisation and Retransmission of the Cyprus Railways. Master Thesis, Politecnico di Milano, Scuola Architettura e Società, Italy. 